\title{
Carbon footprint of an EUR-sized wooden and a plastic pallet
}

\author{
Ivan Deviatkin ${ }^{1,}$, Mika Horttanainen ${ }^{1}$ \\ ${ }^{1}$ Department of Sustainability Science, School of Energy Systems, Lappeenranta-Lahti University of Technology LUT, 53850, \\ Lappeenranta, Finland
}

\begin{abstract}
Pallets are an essential element of existing logistics worldwide. Pallets are simple in structure, yet they can be made of different materials, in varying dimensions, and be marketed via alternative management systems. This paper examines a carbon footprint, an indicator of impact on climate change, of a widely used EUR-size $(1200 \mathrm{~mm}$ x $800 \mathrm{~mm}$ ) pallet made of wood or plastic using the data from previously published literature. The study is geographically representative of Finland, while time and technological representativeness depend on the studies reviewed. On average, the production of a wooden pallet, i.e. cradle-to-gate, has a partial carbon footprint of $5.0 \mathrm{~kg} \mathrm{CO}$-eq. and of $-34 \mathrm{~kg} \mathrm{CO}_{2}$-eq. if accounting for carbon sequestration in wood. Manufacturing of a virgin plastic pallet releases $62 \mathrm{~kg} \mathrm{CO}_{2}$-eq. Given the functional unit of 1000 customer trips and service life of 20 times for a wooden pallet and 66 times for a plastic pallet, the cradle-to-grave impacts of the wooden and the plastic pallets are $17 \mathrm{~kg} \mathrm{CO}$-eq. and $1790 \mathrm{~kg}$ $\mathrm{CO}_{2}$-eq., respectively when the pallets are incinerated at the end-of-life, or $0.34 \mathrm{~kg} \mathrm{CO}_{2}$-eq. per one wooden pallet and $120 \mathrm{~kg} \mathrm{CO}$-eq. per one plastic pallet.
\end{abstract}

\section{Introduction}

The rapid rate of globalisation calls for growing need on logistics and means of transporting products within and across countries and continents. One efficient solution is pallets. European Pallet Association [1] evaluates that the number of EUR, or also referred to as EPAL, pallets manufactured in 2018 increased to 121.8 million pallets from 115.8 million pallets in 2017 indicating a growth of 5.2\%. Furthermore, the Association estimates that there are some 450-500 million EUR pallets being circulated around the globe. The National Wooden Pallet \& Container Association [2] publishes data showing that in the US alone 849 million pallets were produced and repaired in 2016. The Australian market is expected to have 140 million pallets with an annual demand of 56 million pallets in 2017 [3]. Chinese production recorded 700 million pallets in 2012 [4].

The ISO 445 standard [5] defines pallets as "rigid horizontal platforms of minimum height, compatible with handling by pallet trucks and/or forklift trucks and other appropriate handling equipment, used as a base for assembling, loading, storing, handling, stacking, transporting, or displaying goods and loads". Therefore, a wide range of pallets fits under the definition and pallets of all sizes are used in different countries, while preferences are still given to some specific dimensions. The European market is dominated with the EUR-size pallets $(1200 \mathrm{~mm} \times 800 \mathrm{~mm})$, the markets of North America prefer the pallets compliant with the requirements of the Grocery Manufacturers Association (GMA) having dimensions of 48 in./ $1219 \mathrm{~mm} \mathrm{x} 40$ in./1016 mm. The Australian market often uses square pallets sized $1165 \mathrm{~mm}$. The Chinese market makes benefits of using pallets with dimensions of $1200 \mathrm{~mm} \mathrm{x}$ $1000 \mathrm{~mm}$, which are also known as FIN pallets in Europe.

The most commonly used materials for pallets are wood (softwood and hardwood) and plastic (virgin and recycled) and to a lesser extent cardboard, metal, and composites. Wood is the most common material because of its low market price and low investments needed to manufacture wooden pallets. Wooden pallets are assembled from pre-cut timber and secured with nails as required in standards or regulations. Wooden pallets are meant to be repaired if certain parts, e.g. decks or blocks, are damaged. Furthermore, wood is a renewable material whose disposal is relatively simple. Plastic pallets are also widely used, but their use is dominated by sectorspecific requirements, like the medical industry setting specific hygiene standards. Plastic pallets can be more diverse in structure since the can be made of plastic planks and secured with nails the same way as wooden pallets, or they can commonly be manufactured using injection moulding and can be made nestable to save space during their transportation.

Apart from that, pallets can be made to serve different functions. Some pallets are intended for single-use and are discarded after a product reaches its destination. Some pallets are sold after some use, thus transferring their ownership as a deal is made. Other pallets are

\footnotetext{
* Corresponding author: ivan.deviatkin@lut.fi
} 
operated by specific companies who provide a pallets-asa-service co ncept. Such pallets are generally coloured to distinguish between different operators on the market. This is a so-called "pallet pooling" system.

\section{$1.1 \mathrm{Goal}$ of the study}

A significant body of research has been performed so far assessing the environmental impacts of manufacturing, operating, and disposing of wooden and plastic pallets. The study bases on the results of previously published literature which was reviewed in the study by Deviatkin [6]. All in all, 16 studies assessing the impacts of 43 different pallets were used to retrieve the inventory data. This study evaluates the carbon footprint of a typical for Europe wooden and a plastic pallet with the dimensions of $1200 \mathrm{~mm} \times 800 \mathrm{~mm}$. The study focuses only on the impacts on climate change.

\section{Reviewed studies}

The review of life cycle assessment (LCA) studies on pallets was performed as a part of the previously performed study by the authors [6]. During the review, data on 43 pallets were retrieved representing various life cycle stages and pallets. The pallets were classified based on their materials, sizes, structure, and management strategy as shown in Fig. 1. The majority of studied pallets worldwide were made of wood (32 cases out of 43). The most often studied size of the pallets was GMA size of 48 in. by 40 in. which was explained by the higher representativeness of the American market in the studies. If considering the European context, the EUR-size pallet was the most commonly studied one. Also, block-type pallets were more common in Europe than stringer-type pallets. The majority of the pallets studied were pooled pallets.

\section{Goal and scope definition}

\subsection{Goal, function, and functional unit}

The goal of the present study was to assess the climate change impacts of a typical wooden and a plastic pallet as specified later using secondary data retrieved from previously published literature. The study also considered the variation in inventory data available. The function of the studied product system was to transport cargo. Therefore, the functional unit set for the cradle-to-grave study was 1000 customer trips of cargo using either wooden or plastic pallets, whereas the number of pallets needed to perform this number of trips was set to as a reference flow.

\subsection{Product systems and system boundaries}

There were two systems studied: a system utilizing wooden pallets and a system utilizing plastic pallets. Both systems had identical system boundaries and started with the acquisition of raw materials for the process, their potential pre-processing, manufacture of the pallets, their use, repair (only for wooden pallets), and disposal.
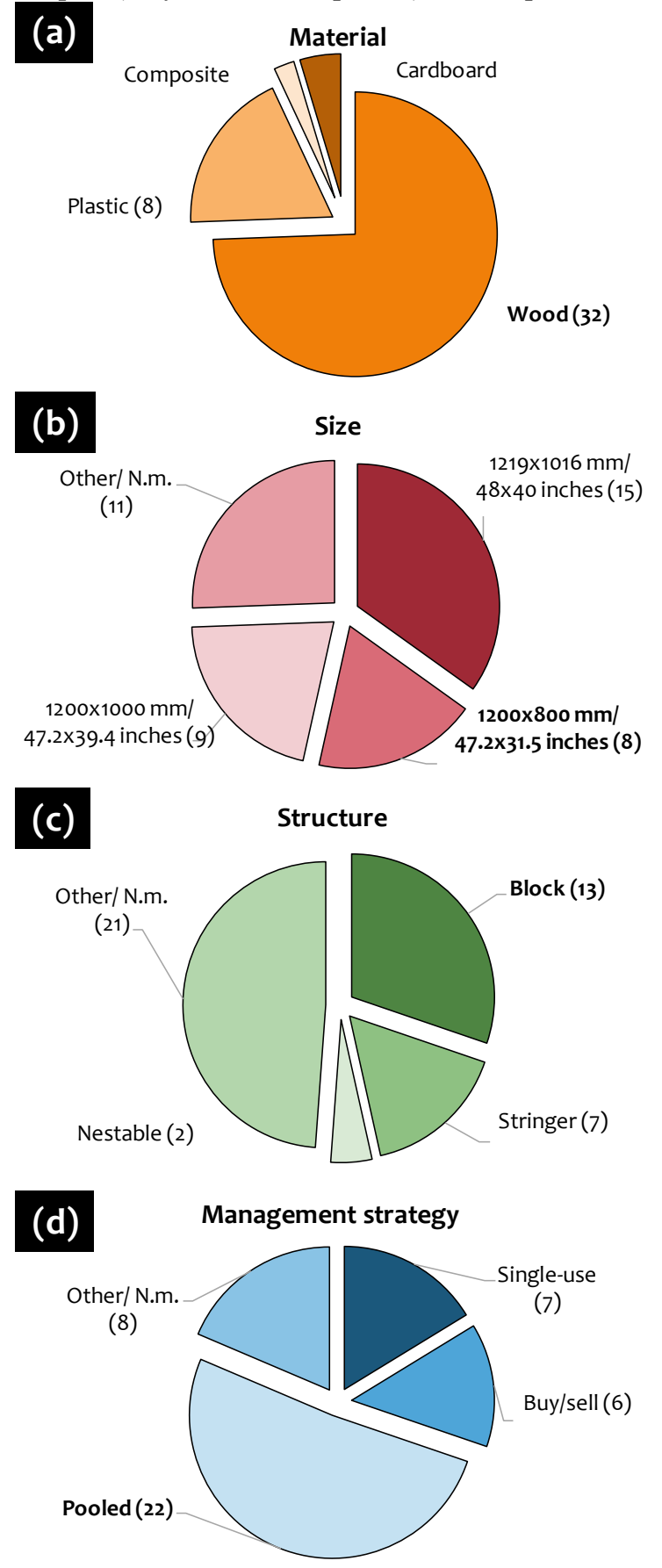

Fig. 1. Pallets studied in review articles by their material (a), size (b), structure (c), and management strategy (d).

The system boundaries of the studied product systems are shown in Fig. 2. The wooden pallets need wood, nail, electricity, and heat for their manufacturing. Once assembled, the pallets were delivered to product manufacturers who use them to deliver products to warehouses and ultimately to retailers and consumers. Then, the pallets were collected by pallet pooling companies, inspected manually or automatically, repaired if needed, and then reused until there are too many faulty points and repair is not economically feasible. At the end- 
of-life, the wooden pallets were modelled as being either incinerated or landfilled with substitution of electricity and heat generated, if any.
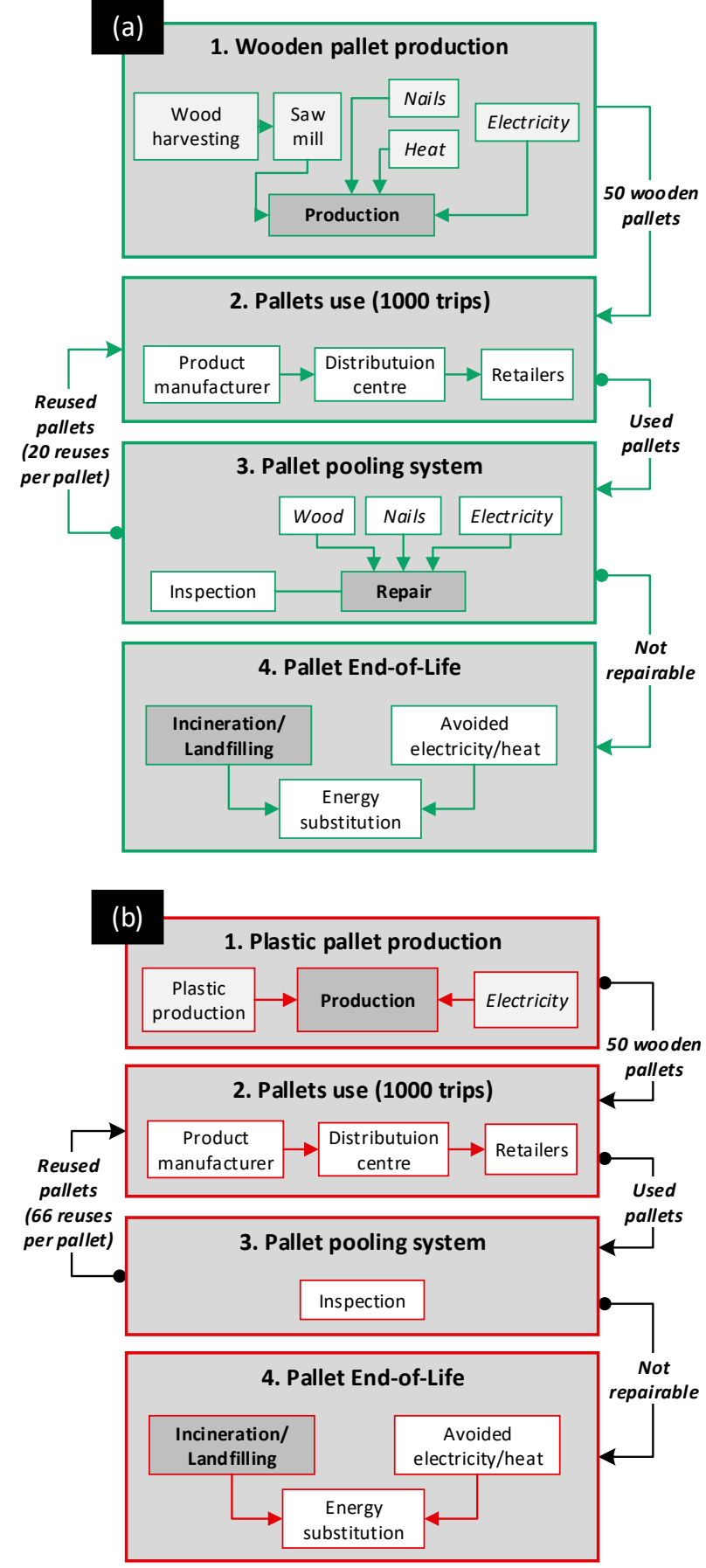

Fig. 2. The system boundaries of a wooden (a) and a plastic pallet (b) product system.

The plastic pallet was modelled to be manufactured via injection moulding making plastic the only raw material needed. Electricity is needed for thermoforming of plastic. The use of the plastic pallets was the same, except that their average number of uses was higher than that of wooden pallets: 66 times versus 20 times meaning that fewer plastic pallets are needed to provide 1000 trips.

\section{Life cycle inventory}

This section compiles inputs to the production processes and the information related to the impacts of the product system.

\subsection{Production of wooden pallets}

The mass of timber required to produce a EUR-size was $17.1 \pm 6.9 \mathrm{~kg}$ based on the review of articles performed by Deviatkin et al. [6]. However, considering that the average weight of a pallet is $20-25 \mathrm{~kg}$, the mass of the pallets from the review study seems to underestimate the mass of timber required. Considering the composition of the pallet and the dimensions of the wooden parts, the bottom-up estimation of timber required was $21.9 \mathrm{~kg}$. The inputs to the wooden pallets production are listed in Table 1. The amounts of inputs to the process, except for timber, were retrieved during a review process.

The inventory for the processes varied. Timber production was modelled after an environmental product declaration (EPD) performed in Finland [7] for sawn products. Other inputs were modelled using $\mathrm{GaBi}$ professional database [8]. Nails were modelled using "EU-28: Fixing material screws stainless steel (EN15804 A1-A3) ts" unit process. The electricity was "FI: Electricity grid mix ts". Thermal energy was "FI: Thermal energy from biomass (solid) ts". The outgoing flow of wood was estimated at the level of $2 \%$ since the timber comes pre-cut to the process decreasing the waste generation.

Table 1. Inputs and outputs of producing a wooden EUR pallet.

\begin{tabular}{|c|c|}
\hline Inputs & Amount \\
\hline Timber & $21.9 \pm 8.8 \mathrm{~kg}$ \\
\hline Nails & $0.38 \pm 0.12 \mathrm{~kg}$ \\
\hline Electricity & $0.69 \pm 0.73 \mathrm{kWh}$ \\
\hline Thermal energy & $4.1 \pm 2.5 \mathrm{MJ}$ \\
\hline Outputs & Amount \\
\hline EUR pallet & $\begin{array}{c}1 \mathrm{pallet} \\
(21.8 \mathrm{~kg})\end{array}$ \\
\hline Wood waste & $0.5 \mathrm{~kg}$ \\
\hline
\end{tabular}

\subsection{Production of plastic pallets}

The plastic pallets were completely made of plastic. The plastic demand was also estimated in the previously performed review. The plastic demand was expressed per $1 \mathrm{~m}^{2}$ of the plastic pallet surface given that the pallets have a similar structure. The inputs to the production process are listed in Table 2.

The inventory for the plastic was "RER: Polyethylene high density granulate". Moulding was modelled using the process "GLO: Plastic injection moulding" with a 
wastage rate of zero per cent and a default energy consumption of $4.5 \mathrm{MJ}$ per $\mathrm{kg}$ of moulded plastic. Electricity type was the same as in the wooden pallet.

Table 2. Inputs and outputs of producing a plastic EUR pallet.

\begin{tabular}{|c|c|}
\hline Inputs & Amount \\
\hline Plastic & $20.0 \pm 6.7 \mathrm{~kg}$ \\
\hline Electricity & $100 \pm 117 \mathrm{kWh}$ \\
\hline Outputs & Amount \\
\hline EUR pallet & 1 pallet $(20 \mathrm{~kg})$ \\
\hline Plastic waste & Not generated \\
\hline
\end{tabular}

\subsection{Repair of wooden pallets}

There was not a sufficient number of articles on the repair of block-type pallets, so the data for the repair was retrieved from the article by Gasol et al. [9]. The inventory of a single repair is listed in Table 3 . The same sources of inventory as for the production of the wooden pallet were used. Each pallet would need 2 repairs per life cycle based on the information on the pallets available on the Finnish market.

Table 3. Inputs of repairing a wooden EUR pallet.

\begin{tabular}{|c|c|}
\hline Inputs & Amount \\
\hline Wood & $1.2 \mathrm{~kg}$ \\
\hline Nails & $56 \mathrm{~g}$ \\
\hline Electricity & $0.17 \mathrm{kWh}$ \\
\hline Outputs & Amount \\
\hline $\begin{array}{c}\text { Mixed wooden and } \\
\text { metal waste }\end{array}$ & $1.3 \mathrm{~kg}$ \\
\hline
\end{tabular}

\subsection{Use phase}

The impacts from the use phase are only related to the transportation of the pallets from the pooling company to the product manufacturers and return logistics from the retailers or customers to the pooling companies. The average number of uses of a wooden pallet was 20 times $(\min -1, \max -83)$. That of a plastic pallet was 66 times $(\min -34, \max -250)$. The transportation distance was assumed to be $150 \pm 50 \mathrm{~km}$. The transportation was modelled using three types of Euro 0-6 trucks: Large - 22 $\mathrm{t}$ payload, Medium - $17.3 \mathrm{t}$ payload, and Small $-9.3 \mathrm{t}$ payload. The medium size truck was used in the default scenario, while the other one truck sizes were used in the uncertainty analysis. The default parameters of the trucks were used [10]. The trucks were fuelled with diesel modelled via the unit process "EU-28: Diesel mix at filling station ts".

\subsection{End-of-life}

There were two options modelled for the end-of-life of the pallets. First was incineration with energy recovery, which is a common disposal method in Finland. Another option was landfilling of pallets which were modelled to show the impacts of the end-of-life method choice on the results.

Incineration of wooden pallets was modelled via the unit process "FI: Untreated wood in waste incineration plant ts", whereas landfilling via "FI: Untreated wood on landfill ts". Incineration of plastics was modelled via the process "FI: PE in waste incineration plant ts" while landfilling via "EU-28: Plastic waste on landfill ts". Prior to incineration, the pallets were crushed and metal separated with a $50 \%$ separation efficiency consuming 78 MJ electricity per $1 \mathrm{~kg}$ of crushed pallets.

During incineration of both pallet types and landfilling wooden pallet, energy is generated. This energy was modelled to substitute average electricity and heat in the Finnish market. The electricity was "FI: Electricity grid mix ts". The heat mix was $36.4 \%$ wooden residues, $30.5 \%$ hard coal, $17.0 \%$ peat, $14.1 \%$ natural gas, $1 \%$ for light fuel oil, and $1 \%$ for heavy fuel oil [11].

\section{Life cycle impact assessment}

The environmental impact was modelled using the impact assessment method named "ISO 14067 GWP 100, Fossil" implemented in GaBi software. The method relies on the characterisation factors of the Firth Assessment Report (AR5) of the Intergovernmental Panel on Climate Change (IPCC). The biogenic carbon has not been reported.

\section{Results}

The results are reported only for the fossil global warming potential (GWP, fossil) per life cycle stage first and then cumulatively over the entire life cycle. Biogenic carbon is not presented in the study. The results are presented based on the average values, whereas the impact of the uncertainty was addressed separately.

\subsection{Pallets production}

The production of a single EUR wooden pallets has a GWP of $5.0 \mathrm{~kg} \mathrm{CO} 2$-eq (Fig. 3). Acquisition of wood contributed $71 \%$ of the impact, provision of nails another $27 \%$, and electricity and heat remaining $2 \%$. The wood, however, is a source of embodied biogenic carbon which accounted for $-34 \mathrm{~kg} \mathrm{CO}$-eq. per wooden pallet. Once incinerated, this biogenic carbon dioxide is releasee back to the atmosphere implying carbon neutrality. The production of the plastic pallet had a significantly higher GWP of $62 \mathrm{~kg} \mathrm{CO}$-eq. with $72 \%$ originating from the provision of $20 \mathrm{~kg}$ of plastic and the remaining $28 \%$ from the electricity supply. Accounting for the high impact of 
plastics production, ca. $2.2 \mathrm{~kg} \mathrm{CO}$-eq. per $\mathrm{kg}$, the use of recycled plastics could be recommended which would only include the impacts from its collection, while the impacts from electricity consumption for thermoforming of plastics would remain the same.

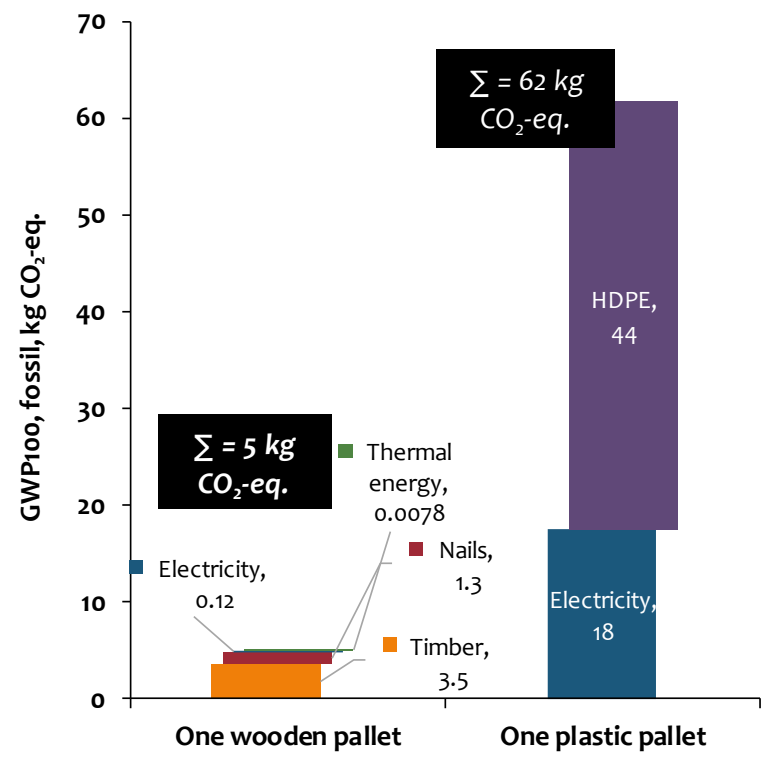

Fig. 3. The partial carbon footprint of one wooden and one plastic pallet.

\subsection{Pallets repair}

The repair of a wooden pallet two times during its lifecycle causes the emissions of $0.84 \mathrm{~kg} \mathrm{CO}$-eq. with the impact being equally spread between wood, nails, and electricity (Fig. 4). The waste from the repair process is not included in the impact but will be a part of the disposal stage of the pallets.

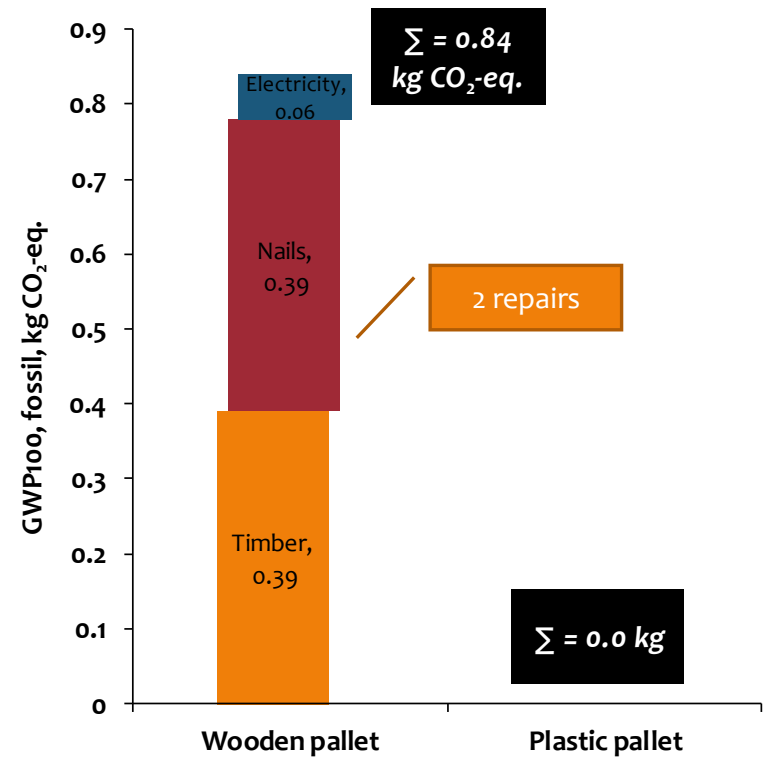

Fig. 4. The partial carbon footprint of two repairs of a wooden pallet during its lifecycle.

\subsection{Pallets use \\ 6.3 Pallets use}


gas generated. In total, the impact was $1.3 \mathrm{~kg} \mathrm{CO}$-eq. Landfilling of the plastic pallet accounted for $1.7 \mathrm{~kg} \mathrm{CO}_{2}-$

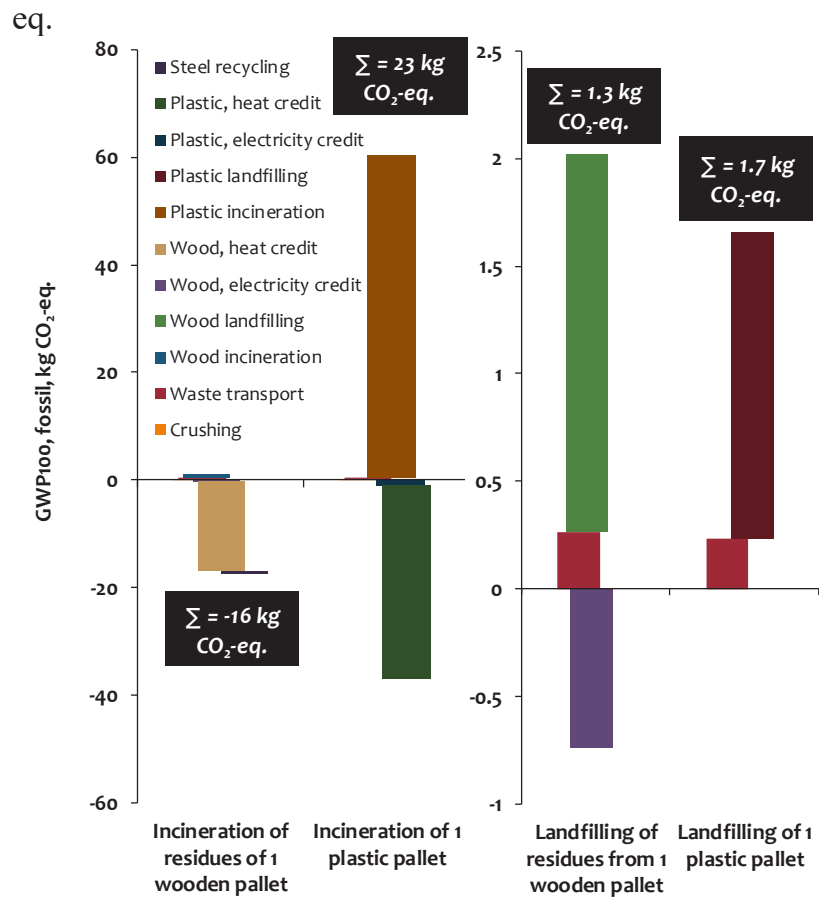

Fig. 6. The partial carbon footprint of incinerating and landfilling of residues generated during a lifecycle of 1 wooden and 1 plastic pallet.

\subsection{Cumulative carbon footprint}

The cumulative results of the carbon footprint calculations were shown in Table 4. The carbon footprint of a product system ensuring 1000 trips by using 50 wooden pallets has a carbon footprint of $17 \mathrm{~kg} \mathrm{CO}_{2}$-eq. if pallets are incinerated and $902 \mathrm{~kg} \mathrm{CO}$-eq. if pallets are landfilled. The footprint of 1 wooden pallet was $0.34 \mathrm{~kg}$ $\mathrm{CO}_{2}$-eq. when the wood is incinerated at its end-of-life with substitution of electricity. If landfilling is practised at the end-of-life the footprint increases to $18 \mathrm{~kg} \mathrm{CO}_{2}$-eq. The lower impact during incineration is due to significant avoided emissions from the substitution of electricity and heat.

Table 4. Carbon footprint of the product system with wooden and plastic pallets, as well as the impact per 1 pallet.

\begin{tabular}{|c|c|c|c|c|}
\hline $\begin{array}{c}\text { Life cycle } \\
\text { stage }\end{array}$ & $\begin{array}{c}\text { Wooden } \\
\text { pallets per } \\
\text { FU }\end{array}$ & $\begin{array}{c}\text { Plastic } \\
\text { pallets } \\
\text { per FU }\end{array}$ & $\begin{array}{c}\text { Per one } \\
\text { wooden } \\
\text { pallet }\end{array}$ & $\begin{array}{c}\text { Per one } \\
\text { plastic } \\
\text { pallet }\end{array}$ \\
\hline Production & 248 & 936 & 5.0 & 62 \\
\hline \multirow{2}{*}{ Repair } & 42 & 0 & 0.84 & 0 \\
\hline \multirow{2}{*}{ Use } & 548 & 498 & 11 & 33 \\
\hline \multirow{2}{*}{ End-of-life1 } & -821 & 353 & -16 & 23 \\
\cline { 2 - 5 } & 64 & 25 & 1.3 & 1.7 \\
\hline \multirow{2}{*}{ Total } & $\mathbf{1 7}$ & $\mathbf{1 7 9 0}$ & $\mathbf{0 . 3 4}$ & $\mathbf{1 2 0}$ \\
\cline { 2 - 5 } & $\mathbf{9 0 2}$ & $\mathbf{1 4 6 0}$ & $\mathbf{1 8}$ & $\mathbf{9 6}$ \\
\hline
\end{tabular}

${ }^{I}$ - the upper row is for incineration, while the lower one is for landfilling.

The plastic pallet had a significantly higher carbon footprint compared to the product system of wooden pallets. Producing 15 pallets, using and disposing of them results in the impact on climate change of $1790 \mathrm{~kg} \mathrm{CO}_{2-}$ eq. if the plastic is incinerated at the end-of-life and 1460 if landfilled. The high impact is due to a large impact from producing plastic and its incineration. If the impact from plastics production could be avoided by using recycled plastic and assuming a zero-burden approach, the impact from plastics incineration will remain the same. The carbon footprint of a single plastic pallet was $120 \mathrm{~kg} \mathrm{CO}$-eq. if incinerated at the end-of-life.

\subsection{Uncertainty analysis}

The variation in the inventory data identified was addressed using a method called simulation decomposition and developed by Kozlova [12]. The method is based on decomposition and colour-coding distributions into groups of outcomes. The method helps to effectively represent the contribution of uncertain parameters on the results which were studied with the example of carbon capture and sequestration [13].
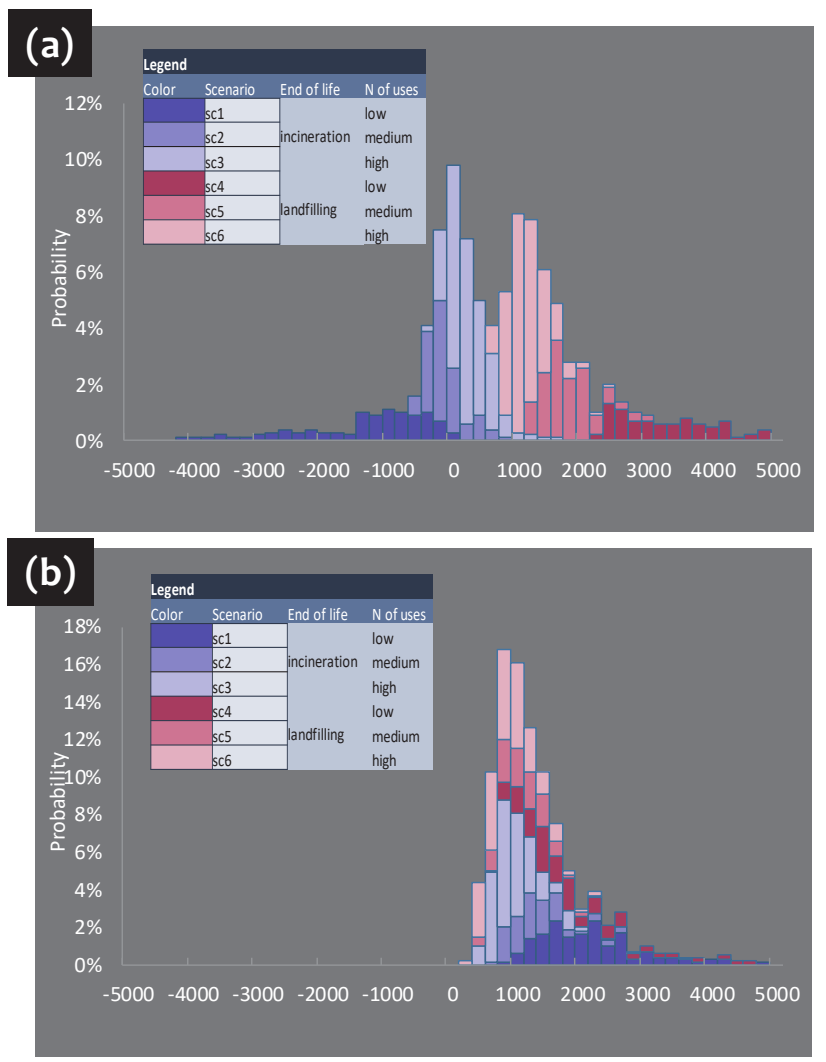

Fig. 7. The uncertainty in the results and contribution of different factors to the uncertainty of the product system studying wooden pallets (a) and plastic pallets (b).

The results of the uncertainty analysis are shown in Fig. 7. The results are grouped into two main categories based on the disposal method: incineration (blue colour) and landfilling (red colour). Those groups were further subdivided into the groups studying the impact of the 
pallets number of uses (low, medium, and high). The results show that the number of uses is directly proportional to the impact on climate change. This is because of the decreasing number of pallets needed per functional unit, and thus lower credits from the end-oflife which significantly outweigh the impact from the production and repair of the pallets. On the contrary, the impact from the plastic pallets reduces significantly with the increasing lifespan of the pallets which results in the decreasing number of pallets needed and lower production and disposal impacts.

\section{Conclusions}

The production of wooden pallets has lower impacts on climate change compared to that of plastic pallets which are related to relatively low impact from wood harvesting and its biogenic nature. By comparison, the production and disposal of plastic emit significant amounts of greenhouse gases, especially during its incineration. Because of this, the impact of the plastic pallets can be reduced by their more cautious use to prolong their lifespan. The wooden pallet, on the contrary, could have a short use period because their incineration at the end-oflife brings a significant reduction of greenhouse gases through avoided electricity and heat.

The study was conducted in the Life IP on waste - Towards a circular economy in Finland (LIFE-IP CIRCWASTEFINLAND) project (LIFE 15 IPE FI 004). Funding for the project was received from the EU Life Integrated program, companies and cities.

\section{References}

1. European Pallet Association e.V., Strong Result: 121.8 Million EPAL Load Carriers in 2018 (2019)

2. National Wooden Pallet \& Container Association, (2019)

3. Centre for Supply Cjaing and Logistics, Australian Pallet Survey 2017 Report (2017)

4. Y. Tang, (2013)

5. SFS-EN ISO 445, Pallets for Materials Handling. Vocabulary (2013)

6. I. Deviatkin, K. Musharof, E. Ernst, and M. Horttanainen, Sustainability 11, (2019)

7. RTS EPD Ympäristöseloste nro. RTS_27_19, Suomalainen Kuivattu Sahatavara Kuusi- Tai Mäntypuusta (2019)

8. Thinkstep, (2017)

9. C. M. Gasol, R. Farreny, X. Gabarrell, and J. Rieradevall, Int. J. Life Cycle Assess. 13, 421 (2008)

10. M. Faltenbacher and J. Hengstler, Documentation for Duty Vehicle Processes (2019)

11. Enegiateollisuus ry, (2018)

12. M. Kozlova, M. Collan, and P. Luukka, Fuzzy Econ. Jounrnal 21, 3 (2017)

13. M. Kozlova and J. S. Yeomans, J. Environ. Informatics Lett. 1, 20 (2019) 